\title{
HISTORY AND DIDACTICS OF MATHEMATICS: A PROBLEMATIC RELATION. SOME CONSIDERATIONS BASED ON FEDERIGO ENRIQUES'S IDEAS
}

\author{
Paolo Bussotti \\ Commission for the Publication of the National Edition of Federigo \\ Enriques's Works, Italy \\ E-mail: paolo.bussotti@alice.it
}

This history of mathematics is a specific and, at the same time, wide field of research with proper methods, journals, congresses and results. However, some questions about its status are without any doubt legitimate. In particular: is the public to whom the work and the publications of the historians of mathematics are addressed, limited to the specialists in this field or is it broader? It often happens that the mathematicians engaged in the active research consider history of mathematics as a sort of curiosity, but nothing really useful for their researches. They are not interested in an inquire on the historical bases of their researches because they are concentrated in discovering new theorems and solving new problems. It difficult to valuate whether and inside which limits this way of thinking is correct. The problem is complex and cannot be dealt with in this context. The other field to which history of mathematics is connected is didactics of mathematics. The link is, in this case, more narrow than the one existing between history of mathematics and advanced mathematical research. The role of history of mathematics inside didactics has been discussed for many decades, at least from the last forty years of the $19^{\text {th }}$ century. The debate born in Europe at that time was wide and profound: one of the main problems was to find the best way to propose the Euclidean geometry to the students of high school because the masterpiece of Euclid, the Elements, are a difficult text from a didactical point of view: they can appear formal to a young student with their apparatus of axioms, notions and definitions, furthermore the dispositions of the different subjects is not always the most appropriate from a didactical point of view and, last but not the least, the theory of proportions, the very core of Euclidean geometry applied in the theory of similarities, is abstract, its application is difficult and not mechanic. Therefore a great French mathematician, Adrien-Marie Legendre (1752-1833), wrote a famous handbook, the Élements de géométrie (first edition 1794, and numerous successive editions). Legendre tried to present Euclidean geometry without resorting to the theory of proportions (one could say: Euclidean geometry without Euclid!). This was possible thanks to a conspicuous recourse to algebra. The problem was the lack of rigour that in many cases characterized Legendre's approach. The worst thing was that after Lagendre's handbook the "Legendrisme" was born. This means: an enormous amount of manuals of geometry were written following his ideas, but these handbooks were far less rigorous than Legendre's one, without the geniality that anyway was present in Legendre's book and full of serious mistakes. This brought to a great discussion on the best way how to teach Euclidean geometry. The positions were variegated: in the 1860s the English mathematician Wilson claimed that Euclid's Elements were an obsolete and not well logically founded text and hence they had to be abandoned in the teaching ${ }^{1}$; on the opposite side after the unification

1 Wilson, J.M., "Euclid as a Textbook of Elementary Geometry", in Educational Times, 1868, pp. 125128. 
PROBLEMS

OF EDUCATION

IN THE $21^{\text {st }}$ CENTURY

Volume 48,2012

6

(1861), in Italy, a radical return to Euclid was decided because the Ministry of Public Education promoted the publication of the Elements by Francesco Brioschi and Enrico Betti (1867) ${ }^{2}$. As a matter of fact the book of Euclid was proposed with some little added explanations and with the exercises. However, the picture of the didactics of mathematics, and first of all of geometry, became more and more complex: in that period the projective geometry, basically thanks to the work of French and German mathematicians ${ }^{3}$, reached a great extension and this branch of mathematics looked to provide a foundation for whole geometry. Partially in connection with this fact, a didactical movement was born: the fusionism, according to which plane geometry and spatial geometry had to be taught together. Fusionist manuals were written, one of the most important mathematicians who followed the fusionism, was Riccardo De Paolis. At the end of the century (1899) one of the most influent books ever written in mathematics was published: Grundlagen der Geometrie by the German mathematician David Hilbert. He presented the abstract axiomatic, that was important not only in the field of foundations of mathematics, but potentially even in didactics, because it was a completely new and more general approach to geometry and to mathematics in general. Furthermore in those years the abstract algebra - in particular group theory, basically thanks to the work of the French mathematicians Camille Jordan (1838-1922), who rediscovered Galois's works, and Henri Poincaré (1854-1912), and to the Norwegian mathematician Sophus Lie (1842-1899) - was developed and it supplied the chance to see many particular mathematical structures framed inside more general algebraic structures. This fact was exploited in didactics, too. Only as an example, Federigo Enriques in his Lezioni di geometria proiettiva per l'università (1898) introduced some concepts of abstract algebra.

Finally, the problems connected with didactics of geometry, the didactical role of the new theories and their relations with the older ones, the analysis of which was the most correct manner to introduce these new theories and if they had to be introduced in the high school or at the university were questions on agenda. In brief: how to conciliate the old with the new? This fundamental question brought the mathematicians community to discuss on the role of history inside didactics of mathematics and, more in general, on the best way to present mathematics to high schools and university students. The great mathematician who had the prominent role was the German Felix Klein (1849-1925). His work was influential in whole Europe. The literature on Klein is abundant. An important Italian mathematician who was partially influenced by Klein, but who developed personal and original ideas was Federigo Enriques (1871-1946). His didactical activity took place in Italy, but his conceptions have a universal validity, this is why we analyse them in this context.

Enriques taught Geometry in the University of Bologna and afterwards in Roma. He was active in institutions and associations connected to didactics of mathematics and sciences. Only to give an example, he was president of the Mathesis (the Association that joins the Italian school teachers of mathematics and physics) in the period 1919-1932. He directly wrote important handbooks for the high schools, the most significant is the Elementi di geometria he wrote with Ugo Amaldi. This book had its first edition in 1903, and numerous successive editions and became the most spread manual in Italian high school (there were various versions, for classical, scientific and professional high schools). He also edited, together with other collaborators, a commented edition of Euclid's Elements. Enriques wrote an article concerning

2 Betti, E. - Brioschi, F., Gli Elementi d'Euclide con note, aggiunte ed esercizi ad uso de' ginnasi e de'licei, Firenze, Le Monnier, 1867.

3 In projective geometry the works of two French mathematicians: Gaspard Monge (1746-1818) and Jean Victor Poncelet (1788-1867) was fundamental for the introduction and the development of the basic concepts between the end of the $18^{\text {th }}$ century and the first half of the $19^{\text {th }}$ century. The German mathematicians Christian von Staudt (1798-1867), August Ferdinand Möbius and the Swiss Jakob Steiner (1796-1863) made the filed of projective geometry wider and more perspicuous introducing new concepts and methods and beginning a critical enquire on foundations. 
the theory of mathematical didactics, too: Insegnamento dinamico ${ }^{4}, 1921$, in which he dealt

with: 1) the correct relation between intuition and logic inside the teaching of mathematics; 2) the opportune level of generalization at which a theory can be presented in the high school; 3) the idea that the separation between the teaching of mathematics and physics is a didactical mistake. All these contributions are important, but perhaps the most significant text to clearly explain the relations Enriques saw between history and didactics of mathematics are the volumes Questioni riguardanti le matematiche elementari ${ }^{5}$, of which Enriques was the editor and where he wrote many contributions. This huge work derives from a deep collaboration between high school teachers and professors. The basic idea is clear: every paper (many of them overcomes 100 pages) traces a historical and at the same time a didactical itinerary. Furthermore many contributions are related to foundations of mathematics because Enriques was sure that the debate on the foundations of mathematics developed at the end of the XIX century could have a didactical role. The work is divided into three parts: 1) Critica dei Principi (Critics of the principles), in two volumes, contains 12 contributions; 2) I problemi classici della geomettria e le equazioni algebriche (The classical problems of geometry and algebraic equations), 1 volume, 11 contributions; 3) Numeri primi e analisi indeterminata. Massimi e minimi (Prime numbers and undetermined analysis. Maxima and minima), 1 volume, 4 contributions. An example can be useful to give the idea of the approach followed in the Questioni: Oscar Chisini in his contribution Sulla teoria elementare degli isoperimetri (On the elementary theory of isoperimetrical figures) traces exactly a historical and didactical itinerary. He begins with explaining the classical theory born in the Hellenistic period. A fundamental reference is Pappo. After that, he explains which were the limits and the problems unsolved by this theory and clarifies how in the $18^{\text {th }}$ and $19^{\text {th }}$ century this theory was made broader and perspicuous. After that, he introduces the novelties due to the great German mathematician Steiner. Finally, he deals with problems connected with the existential demonstrations of maxima and minima and explains the difference between the approach used until the half of the $19^{\text {th }}$ century and the one used afterwards. In this way the picture is clear: every historical step is related to new problems and the student is brought to reason step by step, he sees what kind of questions, what kind of reasoning were used to solve the problems. The mathematical reality is not something imposed by concepts whose introduction can look arbitrary to the student, but only by concepts that derive from the problems themselves. Mathematics looks alive. The student reasons as the great mathematicians of the past, not like a machine that follows only mechanical procedures. In all articles presented in the Questioni, the history of mathematics is functional to didactics, therefore there is not a philological examinations of the sources or profound interpretative ideas; rather, the ideas and the methods of the great mathematicians lived in the past are exposed in didactical

4 Enriques, F, "Insegnamento dinamico", in Periodico di matematiche, series IV, vol. 1, 1921, pp. 6-16. Now this paper can be consulted more easily in the volume: Enriques F, Insegnamento dinamico (with contributions by Franco Ghione and Mauro Moretti), La Spezia, Agorà, 2003, pp. 1-14.

5 The Questioni riguardanti le matematiche elementari have an interesting history: in 1900 Enriques was the editor of Questioni riguardanti la geometria elementare, Bologna, Zanichelli. This was a collective work concerning didactics of geometry. The connections between history and didactics of geometry were well developed. In 1912 a second edition of the work was published. The second edition is wider and partially different from the first one. The contributions do not concern only geometry, but also other fields of mathematics, because of this the new title was Questioni riguardanti le matematiche elementari. The third and last edition was published in 1924-1927 and it is the broadest. In the text we refer to this edition. 
PROBLEMS

OF EDUCATION

IN THE $21^{\text {st }}$ CENTURY

Volume 48,2012

8

key. This was the approach of Enriques and his collaborators to didactics of mathematics.

Many decades have passed from when Enriques wrote his didactical-historical works and exposed his conceptions; didactics of mathematics is a field with many specialists and, after the second world war, numerous significant conceptions have been exposed and applied, but the role of history inside didactics of mathematics is still problematic. In many handbooks for high schools, after the exposition of a certain theory $\mathrm{T}$ - exposition developed without any reference to the history - there are little separated historical sections, in which some brief notices on the mathematicians who invented the theory $\mathrm{T}$ are present. But this approach has no didactical utility because the history results, in this manner, completely separated from the whole mathematical teaching. History of mathematics seems to consist of few curiosities, nothing organic. The problem is not easy: there are some parts of mathematics where the procedures are clear and intuitive, so that the students in general understand the conceptual core of the problems and methods and their utility: this is the case with elementary algebra (algebraic equations, inequalities, polynomial decompositions, and so on) or with trigonometry. So that, maybe history is not necessary. For other problems the situation is different: for example, the concept of logarithm is not so easy to be fully understood, despite most part of students learn how to operate with logarithms. In this case a historical introduction explaining the problems that brought to the discovery of logarithms at the beginning of the $17^{\text {th }}$ century is surely useful. A great problem concerns geometry: today the geometry taught in the high schools is almost exclusively analytical geometry. Synthetic Euclidean geometry has a little role. This looks a serious lack because probably no discipline develops the logical faculties and, at the same time, the fantasy of the young minds as synthetic geometry. Without any doubt, it is difficult because, despite the existence of some general methods, every single problem demands an intuition since there is no mechanical way to solve geometrical problems. It is necessary to work on the figures, to try and to try with different reasoning. Because of this the preference, is accorded to analytical geometry. The history could be important to provide a better comprehension of synthetic geometry to the students: explanations of the problems the Greeks dealt with, use of the figures in Euclid's Elements, role of the axioms, ad absurdum proofs; all this is formative for the students because it helps to reason and to connect mathematics with history, philosophy and logic. Nevertheless, a short time is dedicated to this approach. Separated considerations deserve abstract algebra and mathematical analysis. Abstract algebra has represented a very consistent progress in mathematics because it has allowed to see many theories framed in abstract structures and many important theorems connoting these abstract structures (groups,

6 The literature on the didactics of mathematics in Enriques is rather abundant. I provide here only some indications of texts that are dedicated, partially or completely, to this problem. 1) Bolondi G., "Geometria proiettiva, geometria descrittiva, geometria dello spazio nella scuola italiana", in Franciosi M. (edited by), Prospettiva e geometria dello spazio, Sarzana, Agorà, 2005; 2) Bussotti P., "Un mediocre lettore". Le letture e le idee di Federigo Enriques, Lugano, Agorà, publishing, Lumières Internationales, 2006; 3) Bussotti P., "Federigo Enriques e al didattica della matematica", in Euclide. Giornale di matematica per i giovani, first part n. 6, 24 Febbraio 2012, second part n. 7, 29 aprile 2012. The electronic journal can be freely consulted at http://www.euclide-scuola.org/; 4) Giacardi L., "From Euclid as Textbook to the Giovanni Gentile Reform (1867-1923): Problems, Methods and Debates in Mathematics Teaching in Italy", in Paedagogica Historica, Vol. 42, n. 4-5, August 2006, pp. 587-613. The paper can be consulted at http://www.cimm.ucr. ac.cr/ojs/index.php/.../537; 5) Giacardi L., "Federigo Enriques (1871-1946) and the training of mathematics teachers in Italy", in S. Coen (edited by), Mathematicians in Bologna, 1861-1960, Basel, Springer; 6) Menghini M., "Die euklidische Methode im italienischen Geometrieunterricht seit 1867", in Der Wandel im Lehren und Lernen von Mathematik und Naturwissenschaft, Band I: Mathematik, Schriftenreihe der Pädagogischen Hochschule Heidelberg, Deutscher Studien Verlag, Weinheim, 1994, pp. 138-151; 7) Moretti M., "Insegnamento dinamico. Appunti sull'opera scolastica di Federigo Enriques (1900-1923)", in Enriques F, Insegnamento dinamico, La Spezia, Agorà, 2003, pp. 15-91; 8) Tomasi T., "La questione educativa nell'opera di Enriques", in Pompeo Faracovi O. (edited by), Approssimazione e verità, Livorno, Belforte, 1982, pp. 223-250. 
Paolo BUSSOTTI. History and Didactics of Mathematics: A Problematic Relation. Some Considerations Based on Federigo Enriques's Ideas

\author{
PROBLEMS \\ OF EDUCATION \\ IN THE $21^{\text {st }}$ CENTURY
}

fields, rings, an so on) permitted to discovery fundamental truths in various fields of mathematics (theory of equations, projective geometry, algebraic geometry, topology, and so on). The history that has brought to the development of abstract algebra in the $19^{\text {th }}$ century is complex. In the high schools some notions of abstract algebra are generally introduced without any historical and problematical context, so that for the student it is almost impossible to understand their utility and their profound conceptual meaning. Given the problems dealt with at the high school, abstract algebra can give the idea to be a discipline that makes complicated some problems that in themselves are clear, with a series of obscure, or at least non useful, concepts and methods. From a historical point of view, the problems connected with theory of equations have been one of the bases on which abstract algebra is born. Maybe the explanations of these problems (without entering too difficult and specific details) can help the student to understand why some notions were introduced. But more in general, are these notions of abstract algebra necessary at the high school level? The case of mathematical analysis is completely different: the basic concepts of analysis are intuitive and in general the students address this field of mathematics in a positive manner. Unfortunately a formal approach is too often used in the didactical presentations of mathematical analysis: rather than to give the formal definition of limit or of derivative and integral, it would be maybe preferable to expose the problems that lead the mathematicians of the $17^{\text {th }}$ century to introduce analysis. These problems (connected with the tangents to a curve and the maxima and minima in Fermat and, successively in Leibniz and with physics in Newton) can be understood in the last year of high school and they represent an intuitive approach to analysis. The student can perceive her/himself as a part of a vivid context. Once carried out this kind of introduction, the formalization is necessary because the mere intuition can bring to serious mistakes and, in this case, too, history can have an active role in showing the mistakes deriving from an uncontrolled intuition.

The previous considerations on the opportune use of history of mathematics in a didactical context have, of course, no claim of being systematic. They are only ideas for a discussion that, anyway, looks urgent.

Received: November 14, 2012

Accepted: November 21, 2012

Paolo Bussotti

PhD., Editor, Commission for the Publication of the National Edition of Federigo

Enriques's Works, Via Paolo Lilla, 66, Livorno, 57122 Italy.

E-mail: paolo.bussotti@alice.it 